\title{
Heat recovery by means of a ventilation unit
}

\author{
Dmitrii Khlopitsyn", and Andrey Rymarov \\ Moscow State University of Civil Engineering, Yaroslavskoe shosse, 26, Moscow, 129337, Russia
}

\begin{abstract}
Energy consumption all over the world is constantly growing. To save energy, new technologies are being developed for the efficient use of energy resources. The goal of all new developments is to use less energy to provide the same level of energy supply for technological processes or buildings. The problem of energy saving is relevant for the ventilation system. Together with the removed air, a large amount of heat is lost, which is not advisable. In order to avoid these losses, heat recuperators began to be used, heating the cold supply air due to the warm air removed from the room. This development belongs to the field of energy saving. The goal is to increase efficiency by reheating the air after the heater with the help of a recuperator for a given temperature difference in the supply air before and after the recuperative heat exchanger. The development is a design of a ventilation unit with air removal and supply air ducts, combined into one housing with a separate, according to the "screw" principle, heat transfer wall, for use in the ventilation system in order to ensure an optimal microclimate in the room. Thus, as a result of using the presented device, the efficiency of the room ventilation unit is increased by reducing the energy consumption for heating the supply air with a heater.
\end{abstract}

\section{Introduction}

Today, the emphasis in the design of modern buildings is given not only to technically functional, but energy efficient buildings. The problem of energy saving is relevant for the systems used in the building. Energy prices are high in the world, so the idea of energy conservation has penetrated all areas of construction, including the design and creation of ventilation systems. Financial savings are monitored by optimizing resource consumption [1-6].

A comfortable indoor microclimate is one of the important components of the life support of the entire building. It is the favorable microclimate that contributes to the maintenance of the normal thermal state of the human body, provides thermal comfort and creates the preconditions for a high level of performance [7-10]. Experts say that the energy reserve calculated for heaters and fans in mechanical ventilation systems in old buildings significantly exceeds the electric power for lighting. Energy-saving measures in ventilation systems are a promising task today. Saving the customer's money on the purchase of expensive equipment shows a priority component for the construction project organization. Saving money during operation is an urgent problem. The creation of cost-effective and

\footnotetext{
* Corresponding author: dkhlopitsyn@mail.ru
} 
energy-efficient systems requires completely new approaches and knowledge from the design professionals.

Ventilation professionals use several solutions:

- recirculation;

- recuperation;

- working of geothermal and hydrothermal heat exchangers.

In this article, we will talk about an improved recuperative installation. The principle of energy saving with the help of a recuperative heat exchanger is that the transfer of heat energy occurs between the heat carriers (air-air) through a divided heat transfer wall. The effect of the installation is especially noticeable during the cold period, when the air outside is at a lower temperature than indoors. Recuperation reduces the energy consumption of the air heater in the ventilation system. The fresh air entering the room is heated by the extracted air from the room. The automation controls the supply and discharge of air into the room to maintain an optimal level of $\mathrm{CO} 2$.

Section 2 presents a methodology, an illustration of the application of this development. Section 3 discusses the conclusions of the improved recuperative plant.

\section{Methods, design illustration}

The technical problem solved by the advanced recuperative plant is the development of a mechanical system to create an optimal microclimate in the room. In existing recuperative installations, there is a minus-the area of contact of the surface between the heat carriers for heat transfer.

The technical result of the work is to increase the efficiency of work by increasing the area of the heat transfer surface according to the principle of "screw" and according to the principle of "ribbing" of the surface and with the help of automation. An increase in the area of flow around the exhaust and supply air, affects more energy and money savings for the operating organizations. Automation gives control over the processes taking place in the ventilation unit.

The difference between this design and analogues (plate recuperator, rotary recuperator, recuperator with an intermediate heat carrier, etc.) lies in the fact that the air ducts of the exhaust and supply systems are combined into one cylindrical body with a divided heattransfer wall, according to the principle of "screw", due to it scrolling along the centerline, which is common for the extract and supply air. Also, this heat-transfer surface has fins on both the supply and exhaust air side for greater contact of the heat carrier flows. [11-15]. The air moves in a countercurrent flow through the recuperative unit. It is this movement of the heat carrier flows that increases the heat transfer between the extract air removed from the room and the supply air coming from the street [16-18].The temperature sensor is built into the supply air duct after the recuperative unit, and the temperature heating controller is included in the automatic heater control unit to control and change the supply air parameters. The $\mathrm{CO} 2$ sensor is integrated in the exhaust air duct before the recuperative unit, the $\mathrm{CO} 2$ controller is included in the automatic control unit for the fans to control the supply air and exhaust air. The supply fan and the extract fan change speed synchronously with the control range from $0 \%$ to $100 \%$. The main energy losses in the ventilation system come from the heater and fans. It was the consumption of thermal energy for heating the air 
in the cold season and the consumption of electrical energy for the fans that prompted the creation of the ventilation unit. The temperature sensor sets the comfortable supply air temperature and saves the heater energy. The $\mathrm{CO} 2$ sensor can reduce fatigue and increase the productivity of people in the room, as well as reduce the supply and removal of air when there are few people in the room and therefore carbon dioxide. [19-20].

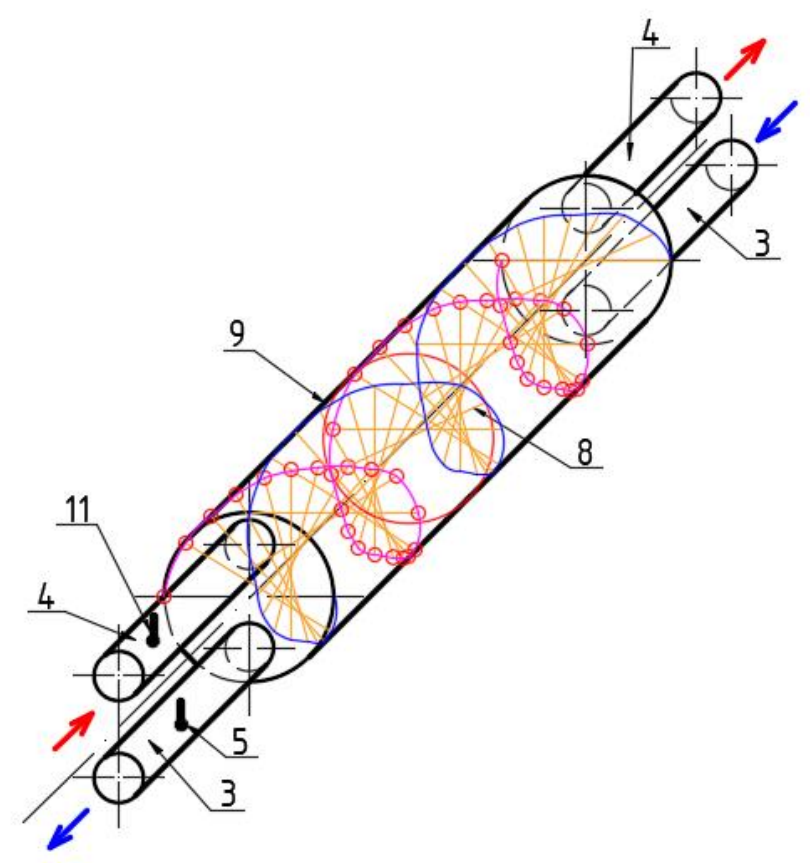

Fig. 1. Isometric view of a recuperative unit.

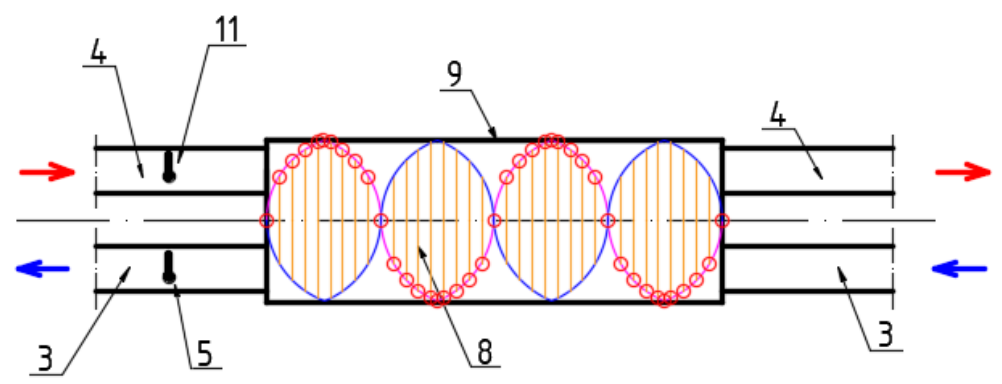

Fig. 2. Longitudinal section of the recuperative unit. 


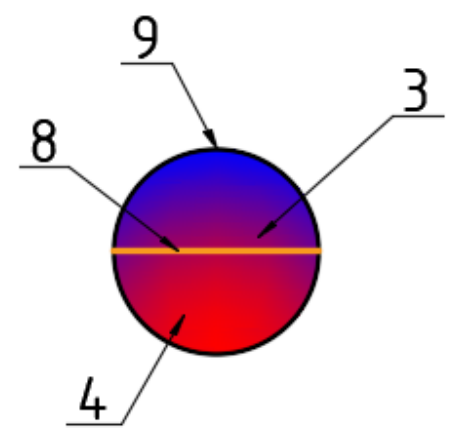

Fig. 3. Cross section of a recuperative unit.

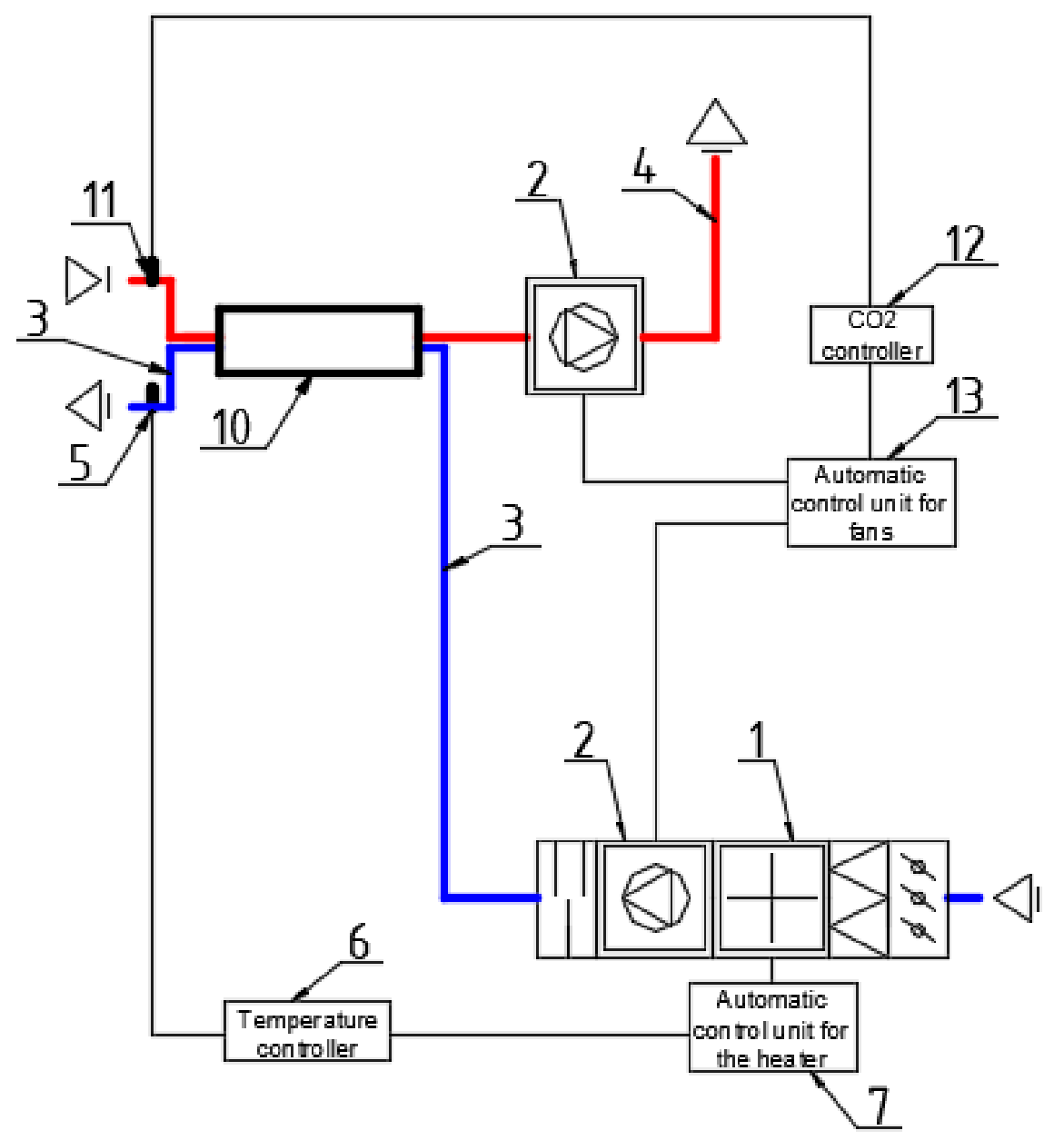

Fig. 4. Schematic diagram of the ventilation unit. 
The device consists of elements:

1 - air heater;

2- fan;

3 - supply air

4 - exhaust air;

5 - temperature sensor;

6 - temperature controller;

7 - automatic control unit for the heater;

8 - heat-transferring wall;

9 - external housing;

10 - recuperator;

11 - CO2 sensor;

12 - CO2 controller;

13 - automatic control unit for the fans.

Let's consider an example of the operation of this ventilation unit.

The supply air taken from the street is heated in the air heater to a certain temperature. After that, the supply air enters the heat recuperator, where it is heated to a certain temperature with the help of exhaust air removed from the room . The temperature sensor is located after the recuperative installation. The temperature sensor is connected to the temperature controller in the automatic control unit, to regulate the temperature in the air heater. The $\mathrm{CO} 2$ sensor is located before the recuperative installation in the exhaust air. The $\mathrm{CO} 2$ sensor is connected to the $\mathrm{CO} 2$ controller in the automatic control unit for the fans, to regulate the volume of the supply air and the exhaust air. This ventilation unit can be used in residential, public and industrial buildings. 


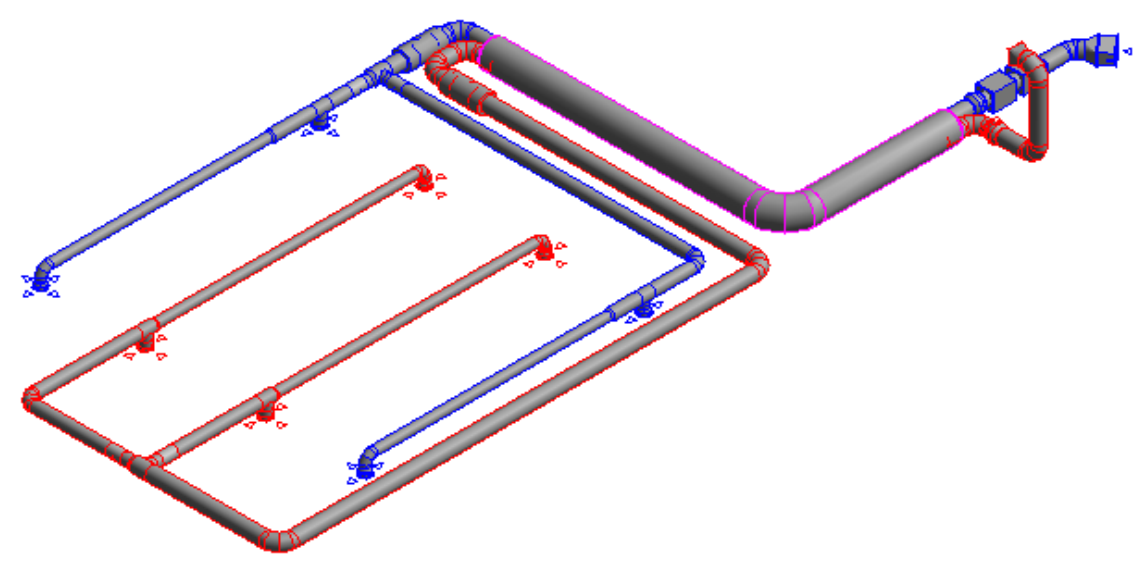

Fig. 5. An example isometric view of a ventilation system.

\section{Conclusions}

From the above analysis, it follows that a special design increases the area of the heattransfer surface, and the automation provides control over the processes in the ventilation unit.

The advantages of this development are:

- comfortable conditions for people to stay indoors;

- reducing the cost of the heater and its costs for thermal energy for heating the supply air;

- reduction in the cost of fans and their energy consumption for the electric drive of the supply and exhaust air at their constant performance to overcome resistance;

- the simplicity of this design;

- control over heating processes in the heater;

- carbon dioxide monitoring;

- reduced electrical costs for the supply and removal of air during the day for fans with changing people's stay in the room;

- automatic adjustment of air parameters.

This design can be used to realize the above benefits. 


\section{References}

1. L. D. Boguslavsky, "Reduction of energy consumption in the operation of heating and ventilation systems", Moscow: Stroyizdat, 286 (1985)

2. O. Ya. Kokorin, "Modern air conditioning systems", Moscow: Publishing house of physical and mathematical literature, 272 (2003)

3. G. I. Stomakhina, I. I. Bobrovitsky, E. G. Malyavina, L. V. Plotnikova, "Heating, ventilation and air conditioning", Moscow: Pantori, 308 (2003)

4. SP 60.13330.2016. Heating, ventilation and air conditioning. Updated version of SNiP 41-01-2003 (as Amended by No. 1) (2016)

5. F. Babota, "Mechanical ventilation systems with heat recoveru for refurbishment projects and new buildings", Technical University of Cluj-Napoca, (2014)

6. C. D Corbin, G. P. Henze, P.A. May-Ostendorp, "Model predictive control optimization environment for real-time commercial building application", Journal of Building Performance Simulation (2013)

7. Yu.S Krasnov, "Recommendations for design, testing and commissioning", M.: TERMOKUL (2006)

8. O.D. Samarin, "The basics of ensuring the microclimate of buildings", 201 (2014)

9. B. Borisov, A. Y. Serginskiy, under the editorship of V. N. Babushkina. "Ventilation and air conditioning in industrial enterprises. Methodical manual", Moscow: Publishing House of the Moscow Power Engineering Institute, 56 (2012)

10. V. Samoilov, "Ventilation and air conditioning", Moscow: Adelant, 239 (2009)

11. A brief overview of the recuperators of ventilation systems. Determination of the efficiency of recuperators //https://www.elibrary.ru/item.asp?id=32399448

12. The ventilation unit to provide indoor climate $/ / \mathrm{https} / / /$ new.fips.ru/registers-docview/fips_servlet?DB=RUPM\&DocNumber $=0000183257 \&$ TypeFile $=\mathrm{html}$

13. GOST 15518-87 Lamellar heat exchangers. Types, parameters and main dimensions (with Change N 1)

14. Development of a program to justify the installation of a recuperator in a ventilation system //https://www.elibrary.ru/item.asp?id=18280284

15. Utilization of heat in cross-plate heat exchangers //https://www.elibrary.ru/item.asp?id=20557156

16. O. M. Alifanov, "Inverse problems in the study of complex heat transfer", Moscow: Janus-K, 300 (2009)

17. Yu. V. Vidin, "Engineering methods for calculating heat transfer problems", Moscow: Infra-M, 480, (2018)

18. Yu. P. Semenov, "Fundamentals of heat and mass transfer", Moscow: Infra-M, 192 (2013)

19. T. V. Arkhipov, "Automatic regulation of ventilation and air conditioning", Moscow: Book on Demand, - 178, (2013)

20. Bondar E. S. et al, "Automation of ventilation and air conditioning systems", K.: Avanpost-Prim, 560 (2005) 